\title{
PERPUSTAKAAN DAN PENDIDIKAN KARAKTER GENERASI MUDA HINDU
}

\author{
I Gusti Ayu Ketut Yuni Masriastri
}

Institut Agama Hindu Negeri Tampung Penyang Palangka Raya

bawiayahfda@gmail.com

$\begin{array}{ll}\text { Riwayat Jurnal } & \\ \text { Artikel diterima } & \text { - } \\ \text { Artikel direvisi } & \text { - } \\ \text { Artikel disetujui } & \text { :- }\end{array}$

\begin{abstract}
Abstrak
Perpustakaan di era modern seperti sekarang ini bukan lagi seperti penilaian mayoritas orang-orang masa lalu. Dimana perpustakaan adalah tempat buku-buku yang dijaga oleh petugas yang berkaca mata tebal, yang dengan setia menjaga buku dan memberikan peluang kepada siapa saja yang meminjam buku.Ditinjau dari sudut pandang yang lebih luas, maka peran perpustakaan merupakan agen perubahan, pembangunan, agen budaya, pengembangan ilmu pengetahuan, teknologi dan pembentukan karakter generasi muda menjadi karakter yang lebih baik dan bertanggung jawab.

Di dalam Undang - Undang RI nomor 43 tahun 2007 tentang perpustakaan menyatakan bahwa dalam rangka mencerdaskan kehidupan bangsa sebagaimana diamanatkan dalam Undang - Undang Dasar Negara Republik Indonesia Tahun 1945, perpustakaan sebagai wahana belajar sepanjang hayat mengembangkan potensi masyarakat agar menjadi manusia yang beriman dan bertaqwa kepada Tuhan Yang Maha Esa, berakhlak mulia, sehat, berilmu, cakap, kreati, mandiri dan menjadi warga Negara yang demokratis serta bertanggung jawab dalam mendukung penyelenggaraan pendidikan nasional.

Pendidikan karakter generasi muda Hindu sangat diperlukan dewasa ini karena tengah berada dalam tantangan dan harapan. Generasi muda Hindu tidak bisa terhindar dari pengaruh zaman modernisasi. Zaman ini berkembang sedemikian rupa yang diimbangi dengan perkembangan teknologi yang demikian pesat. Kemajuan teknologi pada dasarnya dikembangkan dengan tujuan agar segala kehidupan manusia dipermudah dengan harapan manusia mendapatkan pola hidup tenang dan bahagia

Kata Kunci : Perpustakaan, Pendidikan Karakter dan Generasi Muda Hindu
\end{abstract}

\section{Pendahuluan}

Perpustakaan di era modern seperti sekarang inibukan lagi seperti penilaian mayoritas orang-orang masa lalu. Dimana perpustakaan adalah tempat buku-buku yang dijaga oleh petugas yang berkaca mata tebal, yang dengan setia menjaga buku dan memberikan peluang kepada siapa saja yang meminjam buku. Pustakawan di perpustakaan hanya 
ditemani buku-buku kumal dan ruangan tanpa pendingin ruangan. Setelah ribuan tahun hidup dengan teknologi cetak dan ratusan tahun dengan teknologi analog, kelahiran dan perkembangan pesat teknologi digital menimbulkan revolusi mendasar dalam kehidupan manusia, khususnya bagi kalangan pustakawan. Artinya, pustakawan sesungguhnya berperan besar dalam memberikan sumbangan dalam perkembangan peradaban. Akan tetapi, perannya tidak terlihat oleh sebagian besar masyarakat.

Konon, ketika menyebut kata perpustakaan atau library, pemikiran orang merujuk pada suatu medium peradaban manusia yaitu buku. Untuk waktu yang sangat lama, buku menjadi sumber daya pengetahuan yang utama, yang dihimpun oleh perpustakaan. Hal ini terjadi karena posisi perpustakaan dianggap hanya sebagai tempat penyimpanan saja, dan ternyata hingga abad modern anggapan yang demikian masih belum bisa dihilangkan.

Pesatnya kemajuan teknologi, dalam konteks perpustakaan, berpengaruh terhadap berbagai kegiatan yang dilakukan oleh perpustakaan. Teknologi yang didominasi oleh penggunaan computer dianggap telah mampu menggatikan fungsi tenaga manusia dalam menjalankan dan menyelesaikan tugas-tugas yang bisasa dikerjakan manusia, tidak tekecuali pustakawan. Meski tidak seluruh aspek manusia dapat digantikan mesin, namun harus diakui bahwa teknologi mampu menghasilkan produk yang segi kuantitas maupun kualitasnya melebihi produk hasil karya manusia.

Pesatnya kemajuan teknologi, memungkinkan pencari informasi dekat dengan berbagai sumber informasi. Setiap orang dapat dengan mudah mengakses berbagai informasi yang dibutuhkan kapanpun dan dimanapun. Dewasa ini sering timbul pertanyaan, bagaimanakah nasib perpustakaan? Karena perannya sebagai penghubung antara pengguna dan sumber-sumber informasi sudah mulai tergantikan? Mungkinkah perpustakaan tidak dibutuhkan lagi, karena informasi sudah tersedia dimana saja? Akankah perpustakaan akan bertahan dimasa yang akan datang?

Namun kenyataanya, peran perpustakaan kadang tersingkirkan disaat orang-orang ramai membeicarakan tentang era informasi dan masyarakat informasi. Pendit (2007) dalam Wiji Suwarno, 2010: 4 menyatakan bahwa perpustakaan barang kali seperti Ibu si Malin Kundang, yang ditampik ketika putranya telah berhasil. Penampikan yang durhaka itu antara lain si putra melihat betapa tidak pantasnya petampakan dan penampilan si Ibu kalau disandingkan disisnya. Masyarakat informasi adalah si Malin Kundang yang telah menyingkirkan perpustakaan kesudut-sudut tak penting, sebagai mana yang kini dilakukan negaranegara berkembang mauapun maju. Perpustakaan telah menjadi lembaga marjinal, baik diindustri, perdagangan, ilmu pengetahun, bahkan dilembaga pendidikan. Ditinjau dari sudut pandang yang lebih luas, maka peran perpustakaan 


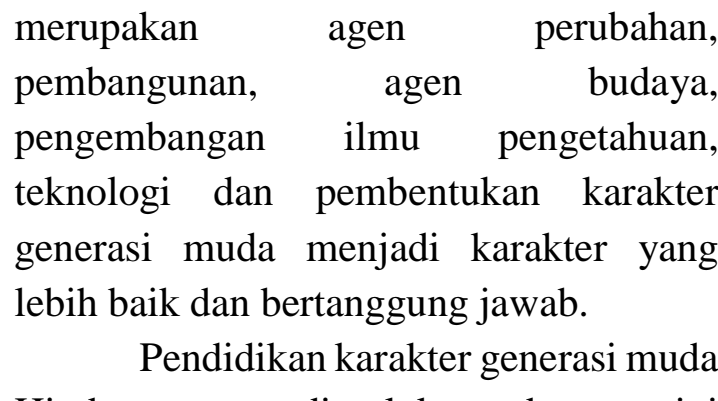

Hindu sangat diperlukan dewasa ini karena tengah berada dalam tantangan dan harapan. I Ketut Sandika Generasi muda Hindu tidak bisa terhindar dari pengaruh zaman modernisasi. Zaman ini berkembang sedemikian rupa yang diimbangi dengan perkembangan teknologi yang demikian pesat. Kemajuan teknologi pada dasarnya dikembangkan dengan tujuan agar segala kehidupan manusia dipermudah dengan harapan manusia mendapatkan pola hidup tenang dan bahagia. Di dalam kitab suci Sarasamuscaya, 304 menyatakan :

Tasmad gunesu rajyate ma dosesu kadacana,

Nirgullo yo hi durbuddhiratmanah so rirucyate.

(Matangnyan haywang tan jenek ring guna,

Prihantakitakin juga ya, haywa

kawesa gumawayang dosa,

Apan ikang wwang durbuddhi dening

tan pagunanya,

Makamusuh awaknya juga ya).

Artinya :

Namun demikian, janganlah orang yang tidak cinta kepada ilmu pengetahuan, tuntutlah dan kejarlah saja akan ilmu itu, jangan hendaknya dipengaruhi oleh perbuatan dosa, sebab orang yang durbudhi (berpekerti jahat) karena tiada ada sifat-sifat satwam padanya, merupakan musuh dirinya sendiri.
Dari sloka di atas dinyatakan bahwa orang yang menuntut ilmu pengetahuan dengan cinta kasih maka ilmu pengetahuan membawa kebaikan karakter dalam hidupnya tetapi jika ilmu pengetahuan dituntut dengan dipengaruhi oleh perbuatan dosa maka akan memberikan karakter yang tidak baik. (Kanjeng, 2003:...)

Pendidikan karakter dan moral bagaikan dua sisi mata uang, kedua harus saling sejalan, tidak bisa dipisahkan. Keduanya menitikberatkan dimensi etis dari individu dan masyarakat serta memeriksa bagaimana standar kebenaran dan kesalahan dikembangkan. Pendidikan karakter merupakan suatu pendekatan holistic yang menghubungkan dimensi moral pendidikan dengan ranah social dari kehidupan generasi muda Hindu. Dalam hal ini perpustakaan mempunyai peranan yang sangat penting dalam pendidikan karakter generasi muda karena perpustakaan merupakan pusat sumber belajar. Perpustakaan merupakan salah satu penunjang dalam meningkatkan sumber belajar yang sekaligus sebagai wadah dari berbagai disipilin ilmu pengetahuan yang juga menunjang atau sebagai sarana dalam mencerdaskan kehidupan bangsa khususnya dibidang pendidikan. Undang-Undang Republik Indonesia nomor 43 tahun 2007 tentang perpustakaan menyatakan :

Bahwa dalam rangka mencerdaskan kehidupan bangsa sebagaimana diamanatkan dalam Undang-Undang Dasar Negara Republik Indonesia tahun 1945, perpustakaan sebagai wahan belajar sepanjang hayat mengembangkan potensi 
masyarakat agar menjadi manusia yang beriman dan bertaqwa kepada tuhan yang maha esa berakhlak mulia, sehat, berilmu, cakap, kreatif, mandiri, dan menjadi warga nrgara yang demokratis serta bertanggung jawab dalam mendukung penyelenggaraan pendidikan nasional.

\section{Pembahasan}

\section{Pengertian Perpustakaan}

Perpustakaan berasal dari kata dasar pustaka. Menurut Kamus Besar Bahasa Indonesia - KBBI (1988), pustaka artinya kitab, buku (Depdikbud:1980) dalam Wiji Suwarno, 2010: 31. Dalam bahasa Inggris dikenal dengan library. Istilah ini berasal dari kata librer atau libri, yang artinya buku (Sulistyo Basuki: 1991,3) dalam Wiji Suwarno, 2010: 31. Dari kata latin tersebut terbentuklah istilah libraries; tentang buku. Dalam bahasa asing lainya perpustakaan disebut bibliotheca (Belanda), yang juga berasal dari bahasa Yunani, biblia yang artinya tentang buku, kitab.

Yang kita tau istilah perpustakaan itu sendiri adalah sebuah ruangan, bagian sebuah gedung, ataupun gedung itu sendiri yang digunakan untuk menyimpan buku dan terbutan lainya yang biasa disimpan menurut tata susunan tertentu untuk digunakan pembaca, bukan untuk dijual (Sulistyo Basuki:1991,3) dalam Wiji Suwarno, 2010: 31. Suatu unit kerja yang substansinya merupakan sumber informasi yang setiap saat dapat digunakan oleh pengguna jasa layannya. Selain buku, didalamnya juga terdapat bahan cetak lainya seperti majalah, laporan, pamphlet, prosiding, manuskrip atau naskah, lembaran music dan berbagai karya media audiovisual seperti film, slide, kaset, piringan hitam, serta bentuk micro seperti microfilm, microfis, dan microburam (micro-opque).Undang-Undang Republik Indonesia nomor 43 tahun 2007 tentang perpustakaan (BAB I pasal 1 ayat 1) menyatakan :

Perpustakaan adalah institusi pengelola koleksi karya tulis, karya cetak, dan/atau karya rekam secara profesional dengan sistem yang baku guna memenuhi kebutuhan pendidikan, penelitian, pelestarian, informasi dan rekreasi para pemustaka.

Dari pengertian di atas dapat disimpulkan bahwa perpustakaan bukan merupakan gudang tumpukan buku-buku yang berdebu dengan penjaga yang berkaca mata tebal dan tidak ramah namun perpustakaan merupakan institusi yang mempunyai peranan yang sangat penting didalam mengelolo koleksi karya tulis, karya cetak dan karya rekam yang dikelola dengan system yang profesional dan baku yang tujuan utama untuk memenuhi kebutuhan masyarakat pengguna (pemustaka) di bidang pendidikan, penelitian, informasi dan rekreasi.

\section{Peran Perpustakaan}

$\begin{array}{lcr}\text { Istilah } & \text { peran disini } & \text { adalah } \\ \text { kedudukan, } & \text { posisi dan } & \text { tempat } \\ \text { perpustakaan } & \text { beroprasional. } & \text { Jika }\end{array}$ memperhatikan konsep dasarnya sebagai pusat informasi, perpustakaan mempunyai peran yang cukup strategis di tengahtengah masyarakat. Baik atau tidaknya suatu perpustakaan tergantung bagaimana kinerjanya. Jika kinerjanya baik tentu 
secara berangsur-angsur mengangkat citra perpustakaan. Pengunjung akan memberi penilaian berdasarkan nilai manfaat yang didapatkan. Wiranto (1997) menyatakan bahwa :

Perpustakaan adalah fasilitas atau tempat menyediakan sarana bahan bacaan. Tujuan dari perpustakaan sendiri, khususnya perpustakaan perguruan tinggi adalah memberikan layanan informasi untuk kegiatan belajar, penelitian dan pengabdian pada masyarakat dalam rangka melaksanakan tri dharma perguruan tinggi.

Wiji Suwarno, 2010: 84 menyatakan bahwa :

Dari kacamata yang lebih luas, peran perpustakaan dapat dianggap sebagai agen perubahan pembangunan agen budaya, dan pengembangan ilmu pengetahuan teknologi. Perubahan selalu terjadi dari waktu ke waktu sesuai dengan perubahan jaman dan juga seiring dengan sifat yang selalu ingin tahu, eksplorer dan berbudaya.

Dari pendapat diatas maka perpustakaan mempunyai peranan di segala aspek kehidupan masyarakat dan juga menjadi agen perubahan dalam berbagai bidang. Dalam bidang pendidikan perpustakaan mempunyai peran ikut mencerdaskan kehidupan bangsa khususnya generasi muda terutama dalam pendidikan karakter.

\section{1) Pendidikan Karakter}

Pendidikan karakter merupakan sebuah istilah yang semakin hari semakin mendapatkan pengakuan dari masyarakat Indonesia. Terlebih dengan dirakannya berbagai ketimpanngan hasil pendidikan dilihat dari perilaku lulusan pendidikan formal saat ini, misalnya korupsi, perkembangan seks bebas pada kalangan remaja, narkoba, tawuran, pembunuhan, perampokan oleh pelajar dan pengangguran lulusan sekolah menengah dan atas. Semua terasa lebih kuat ketika Indonesia dilanda krisis dan tidak kunjung beranjak dari krisis yang dialami. Akar dari semua tindakan yang jahat dan buruk, tindakan kejahatan terletak pada hilangnya karakter. Karakter yang kuat adalah fundamental yang memberikan kemampuan kepada populasi manusia untuk hidup bersama dalam kedamaian serta membentuk dunia yang dipenuhi dengan kebaikan dan kebajikan yang bebas dari kekerasan dan tidakan tidak bermoral. Helen G.Douglas dalam Muchlas Samani,2014: 41 menyatakan bahwa :

Character Isn't Inherited. One builds its daily by the way one thinks and acts, thought by thought, action by action.

(Karakter tidak diwariskan, tetapi sesuatu yang dibangun secara berkesinambungan hari demi hari melalui pikiran dan perbuatan, pikiran demi pikiran, tindakan demi tindakan).

Menurut Kamus Besar Bahasa Indonesia-KBBI, 2008 menyatakan : karakter merupakan sifat sifat kejiwaan, akhlak atau budi pekerti yang membedakan seseorang dengan yang lain. Muchlas Samani, 2014 : 43 menyatakan : Karakter dapat dimaknai sebagai nilai dasar yang membangun pribadi seseorang, terbentuk baik karena pengaruh hereditas maupun pengaruh lingkungan, yang membedakannya dengan orang lain, serta 
diwujudkan dalam sikap dan perilakunya dalam kehidupan sehari-hari.

Ngainun Naim, 2012: 55 menyatakan: karakter mengacu kepada serangkaian sikap (attitude), perilaku (behaviors), motivasi (motivations), dan keterampilan (skills).Karakter meliputi sikap sepertikeinginan untuk melakukan hal yangb terbaik, kapasitas intelektual, seperti berfikir kritis dan alasan moral, perilaku seperti jujur dan bertanggung jawab, mempertahankan prinsip-prinsip moral dalam situasi penuh ketidakaadilan serta kecakapan emosional dan interpersonal.

Dari beberapa pengertian karakter di atas maka pendidikan karakter dapat diartikan sebagai pendidikan yang mengembangkan karakter yang mulia (good character) dari peserta didik dengan mempraktikkan dan mengajarkan nilainilai moral dan pengambilan keputusan yang beradab dalam hubungan dengan sesama manusia maupun dalam hubungannya dengan tuhan. Di dalam kitab suci Sarasamuscaya, 77 menyatakan :

Kayena manasa vaca yadabhiksnam nisevyate,

Tadevapaharatyenam tasmat

kalyanamacaret.

(apan ikang kinatahwan ikang wwang, kolahanya,

Kangenangenanya, kocapanya, ya juga bwat umalap ikang wwang,

Jenek katahwan irika wih).

Artinya :

Sebab yang membuat orang dikenal adalah perbuatannya, pikiranya, ucapanucapannya; hal itulah yang sangat menarik perhatian orang, untuk mengetahui kepribadian seseorang. Oleh karena itu hendaklah yang baik itu selalu dibiasakan dalam laksana, perkataan dan pikiran.

Dari sloka di atas menyatakn bahwa kepribadian atau karakter seseorang dapat dilihat dari tingkah laku dan ucapan. Orang yang mempunyai karakter yang baik pasti disukai banyak orang serta tingkah lakunya akan dijadikan contoh banyak orang. Karakter merupakan kebiasaan, oleh karena itu hendaknya kita membiasakan diri selalu berbuat baik. Pendidikan karakter sangat penting sedini mungkin diberikan kepada generasi muda. Pemerintah Indonesia sudah mulai melaksanakan pendidikan karakter melalui kurikulum 2013 dimana yang diajarkan di sekolah bukan hanya kemampuan akademis semata tetapi yamg terpenting adalah bagaimana membentuk karakter yang baik para generasi muda sehingga nantinya mereka tahu dan sadar mana perbuatan yang baik dan tidak baik. Di dalam kitab suci Sarasamuscaya, 78 menyatakan :

Vaca karmanicitte ca durlabhah sagunejanah, yasya

Tvepamvdhim karyam sa janah sarvadhurlabhah.

(wuwusnyan durlabha ikang saguna, ring kaya,

Wak, manah, hana pwa mangkana shira wokasning

Durlabha, tan mangkanya juga airan pinakeweh).

Artinya :

Dikatakan amat sukar untuk menterapkan sifat guna (satwa) dalam perbuatan, perkataan, dan pikiran ; meskipun hal itu merupakan kesulitan yang amat besar, 
seyogyanya janganlah hal itu dianggap penghalang merupakan kesulitan (harus terus berusaha sampai berhasil.

Dari sloka di atas menyatakan bahwa sangat sulit membentuk karakter yang baik tetapi kita tidak boleh menyerah begitu saja. Seperti pepatah mengatakan dimana ada niat dan keinginan yang baik disana pasti ada jalan yang baik. Janganlah tantangan dan kesulitan itu dijadikan penghalang untuk menjadi generasi yang berkarakter baik.

Pendidikan karakter merupakan sebuah istilah yang semakin hari semakin mendapatkan pengakuan dari masyarakat Indonesia. Dharma Kesuma, 2013: 5 mendefinisikan pendidikan karakter dalam seting sekolah sebagai "pembelajaran yang mengarah pada penguatan dan pengembangan perilaku anak secara utuh yang didasarkan pada suatu nilai tertentu yang dirujuk oleh sekolah". Definisi ini mengandung makna : 1) pendidikan karakter merupakan pendidikan yang terintegrasi dengan pembelajaran yang terjadi pada semua mata pelajaran. 2) diarahkan pada penguatan dan pengembangan perilaku anak secara utuh. Asumsi anak merupakan organisme manusia yang memiliki potensi untuk dikuatkan dan dikembangkan. 3) penguatan dan pengembangan perilaku didasari oleh nilai yang dirujuk sekolah (lembaga). Fatchul Mu'in, 2011: 323 menyatakan: jika pendidikan dipahami dalam arti luas sebagai proses penyadaran, pencerdasan, dan pembangunan mental atau karakter bukan hanya identic dengan sekolah tetapi berkaitan dengan proses kebudayaan yang mempunyai kemampuan untuk mengarahkan kesadaran, memasok informasi, membentuk cara pandang dan membangun karakter generasi muda.

\section{Generasi Muda Hindu}

Generasi muda merupakan orangorang yang memiliki intelektual dan berpandangan luas ke depan, apalagi generasi muda merupakan tonggak estafet kepemmimpinan yang sangat perlu diberikan kemampuan dan pemahan mental spriritualitas religiusitas. Generasi muda harus diberikan pendidikan karakter agar mempunyai karakter yang baik dan berbudi pekerti karena mereka bangsa Indonesia berada di pundak mereka. Menurut Kamus Besar Bahasa IndonesiaKBBI, 2008: 440 bahwa kata generasi berarti sekalian orang yang kira-kira sama waktu hidupnya, angkatan, masa orangorang seangkatan hidup. Menurut Kamus Besar Bahasa Indonesia-KBBI, 2008: 932 kata muda artinya belum sampai setengah umur, belum matang, belum cukup umur, belum waktunya, belum lama ada, yang kedua.

Generasi muda Hindu yang dimaksut disini adalah sekumpulan orang yang seangkatan atau seusia yang seiman atau beragama Hindu yang sama-sama mendapatkan pendidikan karakter agar mereka mempunyai karakter yang baik dan sebagai generasi muda yang berketuhanan (tunduk patuh pada konsep ketuhanan) dan mengemban amanah sebagai pemimpin bangsa yang bermental idiologi Pancasila dan bermental spriritual, yaitu mempunyai keyakinan (sradha) yang mempunyai sradha dan tekun melaksanakan ajaran agama. Di 
dalam kitab suci Sarasamuscaya, 27 menyatakan :

Yuvaiva dharmmamanvicched yuva vittam yuva

Srutam, tiryyagbhavati vai dharba utpatan na ca viddyati.

(matangnya deyaning wwang, pengponganikang

Kayowanan, panedeng ning awak, sadhanakena ri

Karjananing dharma, artha, jnana, kunang apan tan

Pada kasaktining atuha lawan rare, drstanta nahan

Yangalalang atuha, telas rumepa, marin alandep ika.)

Artinya:

Karenanya perilaku seseorang; hendaklah digunakan sebaik-baiknya masa muda, selagi badan sedang kuatnya, hendaklah dipergunakan untuk usaha menuntut dharma, artha dan ilmu pengetahuan, sebab tidak sama kekuatan orang tua denga kekuatan anak muda; contohnya ialah seperti ilalang yang telah tua itu menjadi rebah, dan ujungnya itu tidak tajam lagi.

Sloka diatas menyatakan bahwa generasi muda agar menggunakan masa mudanya dengan sebaik-baiknya untuk menuntut ilmu pengetahuan karena masa muda pikiran masih sangat tajam untuk menangkap dan mencerna berbagai macam pengetahuan. Inilah hakekat masa muda bagi generasi muda Hindu, hendaknya mensyukuri usia muda dengan melakukan segala perbuatan baik.

\section{Peranan Perpustakaan dalam Pendidikan Karakter Generasi Muda Hindu}

Perpustakaan menurut fungsinya memosisikan diri sebagai tempat yang menyediakan berbagai informasi, baik yang berkaitan dengan social, politik, maupun ekonomi, dan informasi lainnya. Diperguruan tinggi perpustakaan sering diistilahkan sebagai jantungnya perguruan tinggi. Hal ini berarti perpustakaan memiliki peranan penting di dunia pendidikan jika jantungnya lemah maka tubuh lainya akan menjadi lemah. Artinya jika perpustakaan lemah maka akan berpengaruh tehadap institusi/lembaganya. Sebaliknya jika jantungnya baik maka tubuh yang lainya akan ikut baik juga. Dengan demikian jika perpustkaan baik maka institusi/lembaganya baik juga. Perpustakaan dan lembaga pendidikan sekarang ini tidak dapat dipisahkan, keduanya akan mempunyai nilai jika keduanya ada.

Dari uraian di atas terlihat bahwa perpustakaan mempunyai peranan yang besar dalam pendidikan karakter generasi muda Hindu. Agar peran perpustakaan bisa terlaksana maka satu dasawarsa terakhir perpustakaan mengalami perkembangan cukup signifikan. Dari penggunaan fasilitas yang manual, kemudian otomasi perpustakaan, sampai pada tahap digitalisasi. Perpustakaan harus mengikuti kondisi tersebut demi memenuhi kebutuhan pemustaka dan mengikuti perkembangan ilmu pengetahuan dan teknologi. Slogan mencerdaskan kehudupan bangsa sudah melekat dengan eksistensi perpustakaan saat ini dan diharapkan kedepan 
perpustakaan bisa menjadi agen perubahan (agen of change)yang bisa berkontribusi dalam pendidkan karakter generasi muda. Sasaran perpustakaan kedepan adalah untuk mencari berbagai data yang kemudian diseleksi dan dikelola sesuai dengan standar perpustakaan sehingga menjadi informasi yang layak saji bagi pemustaka. Informasi yang diakses oleh pemustaka menjadi suatu pengetahuan yang berguna dan diharapkan ketika pemustaka sudah memiliki ilmu pengetahuan akan berkarakter baik dan menjadi bijaksana dalam menentukan sikap maupundalam mengambil keputusan. Jika hidup sudah mempunyai karakter yang baik dapat dikatakan ia sudah menjadi orang-orang yang terdidik, dan memiliki pengetahuan serta wawasan yang luas. Dengan demikian sasaran terwujudnya generasi muda Hindu berkarakter baik dengan sendirinya akan tercapai.

\section{Penutup}

Perpustakaan seperti sebuah permata yang hilang dan telah ditemukan. Betapa tidak, dulu perpustakaan hanya dianggap sebagai tempat buku saja kini berkembang menjadi pusat sumber daya informasi yang artinya, perpustakaan tidak lagi sebagai penyimpanan buku melainkan sudah berkembang menjadi tempat dimana pengguna (user) mampu menciptakan sesuatu yang mampu dibaca dan digunakan orang lain. Perpustakaan pada era ini dipilih sebagai agen perubahan (agent of change) karena perpustakaan merupakan pusat segala jenis informasi dan ilmu pengetahuan dan diperpustakaan pula generasi muda intelektual dilahirkan.

$$
\text { Perpustakaan dan dunia }
$$

kependidikan tidak dapat dipisahkan satu sama lain, saling berkaitan dan bergantung satu sama lain. Karena peran itulah, maka perpustakaan berupaya ikut andil menjadi bagian dalam pendidikan karakter generasi muda. Karena seperti kita ketahui generasi muda sekarang banyak mengalami kemerosotan moral dan untuk mengatasi itu maka pemerintah menggalakkan pendidikan karakter dari usia dini. Perpustakaan merupakan pusat informasi dan tempat belajar yang paling representative yang diharapkan mampu memberikan pendidikan karakter kepada generasi muda melalui informasi dan berbagai macam pengetahuan yang menjadi koleksi perpustakaan dan bisa dibaca dan diakses oleh mereka. Dengan banyak pengetahuan dan informasi positif yang diperoleh diharapkan generasi muda mempunyai karakter yang baik dan bisa membentengi diri dari pengaruh negative kemajuan zaman karena mereka adalah kader-kader masa depan bangsa.

\section{Daftar Pustaka}

Departemen Pendidikan Nasional, 2008. Kamus Besar Bahasa Indonesia Pusat Bahasa. Jakarta: PT Gramedia.

Dharma Kesuma, 2013. Pendidikan Karakter Kajian Teori dan Praktek di Sekolah. Bandung: PT Remaja Rosdakarya.

Fatchul Mu'in, 2011. Pendidikan Karakter Konstruksi Teoritik \& Praktik. Jogjakarta: Ar-Ruzz Media. 
Julian M, James, 2008. Belajar Kepribadian. Jogjakarta: Baca.

Muchlas Samani, 2014. Konsep dan Model Pendidikan Karakter. Bandung: PT Remaja Rosdakarya.

Muhammad Kailani Eryono, 2015. Pengantar Ilmu Perpustakaan "bahan ajar diklat calon pustakawan tingkat ahli”. Surabaya: Paramita.

Ngainun Naim, 2012. Character Buiiding. Jogjakarta: Ar-Ruzz Media.

Ngurah, I Gusti Made, 2006. Buku Pendidikan Agama Hindu untuk Perguruan Tinggi. Surabaya: Paramita.

Perpustakaan Nasional RI, 2010. UndangUndang Republik Indonesia No.43 tahun 2007 tentang perpustakaan. Jakarta: Sekretariat Utama Perpustakaan Nasional RI.

Sandika, I Ketut, 2011. Pendidikan menurut Weda. Denpasar: Pustaka Bali Post

Surpha, I Wayan, 2005. Pengantar Hukum Hindu. Surabaya: Paramita.

Wiji Suwarno, 2010. Ilmu Perpustakaan dan Kode EtikPustakawan. Yogyakarta : AR - Ruzz Media.

Wiji Suwarno, 2010. Pengetahuan Dasar Kepustakaan. Bogor : Ghalia Indonesia

Yusuf, Pawit.M, 2009. Ilmu Informasi, Komunikasi dan Kepustakaan. Jakarta: PT Bumi Aksara 